\title{
Special Issue IBIS 2011: The Biogeochemical Silica Cycle From Land to Ocean
}

\author{
Eric Struyf • Daniel J. Conley
}

Published online: 29 December 2012

(C) Springer Science+Business Media Dordrecht 2012

Following the 2010 IBIS (Isotopes and Biogenic Silica) meeting in Swansea, it was decided to take IBIS to the European continent for the first time in 2011, after the first four meetings were held in the UK. This event was an important transition for the internationalization of IBIS. Originally aimed at bringing together British researchers working on isotopes in biogenic silica in aquatic ecosystems (http://www.bgs.ac.uk/ ibis/home.html), IBIS has now matured into a dynamic European based group investigating biogeochemical cycling from the continents to the ocean, with an emphasis on the interference of biota (from singlecelled diatoms to entire ecosystems) in the silicon cycle. Antwerp, Belgium was chosen as the location for the 2011 meeting. The international cooperation continues with the 2012 meeting held in Hamburg, Germany, while the 2013 meeting will take place in Helsinki, Finland.

The Antwerp IBIS meeting was the largest IBIS meeting welcoming 71 scientists with 13 different nationalities, including for the first time participants from outside Europe. The theme of the meeting was biogeochemical silica cycling from land to ocean in all its aspects. 30 oral presentations were delivered,

\footnotetext{
E. Struyf $(\bowtie)$

Department of Biology, Ecosystem Management Research Group, University of Antwerp, Universiteitsplein 1C, 2610 Wilrijk, Belgium

e-mail: eric.struyf@ua.ac.be

D. J. Conley

Department of Geology, Lund University, Sölvegatan 12, 22362 Lund, Sweden

e-mail: daniel.conley@geol.lu.se
}

including keynotes by Philippe Van Cappellen (University of Waterloo, Canada), Olivier Ragueneau (Laboratoire des Sciences de l'Environnement Marin, France) and Jean-Thomas Cornelis (Université catholique de Louvain, Belgium), while the poster session hosted another 20 presentations. The articles in this special issue reflect the diversity of topics discussed, from studies on isotopes in biogenic silica in the ocean aimed at unraveling geo-climate variability, to studies focusing on the cascade of ecosystems, both terrestrial and aquatic and natural and cultivated, influencing transport of silica through the continents to the ocean.

Starting in Swansea, it was decided that beer, which contains significant quantities of silica, should be a central component of the meeting's social activities. Belgium has a long heritage of beer brewing: beer is an importance source of silica to the human body. The organizers took this suggestion seriously. Dinner on the first evening was organized in an Antwerp microbrewery. During the ice-breaker, Martin Hodson presented a talk on "beer, barley, bones and Belgium", and participants were informed about the dissolved silica content of the beer they were consuming. A large dataset of Belgian beer dissolved Si content was gathered by the authors for this purpose. The article in this special issue by Schoelynck et al. reveals controlling factors on the Si content of Belgian beer [1].

Snelling et al. and Berg et al. contributed to the sessions on the study of isotopes in ocean biogenic silica [2, 3]. Snelling et al. presented a micro-manipulation technique for the extractions of diatoms from ocean sediments, showing how geochemical and isotope analysis on the extracted diatoms can shed light on past climate variability. Berg et al. further build on this topic, presenting a study on controlling factors on $\mathrm{C}$ isotopes 
in the biogenic silica in coastal marine sediments from East Antarctica.

Estuaries are important filters on the delivery of both biogenic and dissolved silica to the ocean and the delivery is essential for the ocean silica balance [4]. Several authors focused on our evolving understanding of biogeochemical Si cycling in estuaries. Lehtimäki et al. studied the dynamics of amorphous silica in the Vantaa River estuary [5]. Amorphous silica is an important component of reactive silica delivery to the coastal zone. As all biogenic silica is amorphous, but not all amorphous silica is biogenic (pedogenic and adsorption processes can reprecipitate DSi as amorphous $\mathrm{Si}$ ), it is important to develop techniques to separate both amorphous Si pools. Siipola et al. present a new approach to achieve this goal [6], while Tallberg et al. performed an experiment to distinguish the role of both pools in the release of dissolved silica from sediment cores [7].

Tidal marshes have also been identified as major processors of biogenic silica. Weiss et al. assessed the role of tidal marshes in the inner Elbe estuary for silica processing [8], while Jacobs et al. focused on the increased accumulation of the vegetation biogenic $\mathrm{Si}$ pool in a recently restored tidal marsh [9].

Before Si can reach the ocean, terrestrial ecosystems exert an important influence on the continental $\mathrm{Si}$ mobilization [10]. This topic has received ever-growing attention in the past decade: it is now clear that while lithology and mineral weathering are prime controllers on potential terrestrial $\mathrm{Si}$ mobilization, the ecosystem filter (with large quantities of weathered Si stored in terrestrial soils and vegetation as amorphous silica) often determines the amount transported to rivers. Viaroli et al. provide an exhaustive overview of the role of both cultivated and natural ecosystems in the Po watershed in determining dissolved silica fluxes [11]. Modeling the processes that are at the base of this ecosystem control of continental Si fluxes has remained mainly empirical: Ronchi et al. have summarized knowledge on processes affecting terrestrial-aquatic transfer of $\mathrm{Si}$ from soils to rivers, and propose a mechanistic approach to modeling ecosystem Si transfers [12].

The multitude of topics in this special issue is witness to the diversity of challenges that still exist in understanding biological interactions in the biogeochemical Si cycle. It is our hope that the IBIS meetings, and IBIS publications including this special issue, will stimulate the scientific community to meet these challenges. This is key to increasing our understanding of the cycle of this fascinating element, which affects living beings (including humans) from the most remote terrestrial ecosystems to the ocean, where silica-depositing diatoms are the primary permanent sink for atmospheric $\mathrm{CO}_{2}$ on centennial timescales.

\section{References}

1. Schoelynck J, Beauchard $\mathrm{O}$, Jacobs S, Bal K, Barão L, Smis A et al (2013) Dissolved silicon and its origin in Belgian beers-a multivariate analysis. Silicon. doi:10.1007/s12633-012-9133-Z

2. Snelling A, Swann GA, Leng M, Pike J (2013) A micro-manipulation technique for the purification of diatoms for isotope and geochemical analysis. Silicon. doi:10.1007/s12633-012-9115-1

3. Berg S, Leng M, Kendrick C, Cremer H, Wagner B (2013) Bulk sediment and diatom silica carbon isotope composition from coastal marine sediments off East Antarctica. Silicon. doi:10.1007/s12633-012-9113-3

4. Tréguer PJ, De La Rocha CL (2012) The world ocean silica cycle. Ann Rev Marine Sci, 5. doi:10.1146/annurevmarine-121211-172346

5. Lehtimäki M, Tallberg P, Siipola V (2013) Seasonal dynamics of amorphous silica in vantaa river estuary. Silicon. doi:10.1007/s12633-012-9126-y

6. Siipola V, Mäntyniemi S, Lehtimäki $M$, Tallberg $P$ (2013) Separating biogenic and adsorbed pools of silicon in sediments using bayesian inference. Silicon. doi:10.1007/s12633-012-9120-4

7. Tallberg P, Lehtoranta J, Hietanen S (2013) Silicate release from sand-manipulated sediment cores: biogenic or adsorbed Si? Silicon. doi:10.1007/s12633-012-9127-x

8. Weiss A, Amann T, Hartmann J (2013) Silica dynamics of tidal marshes in the inner Elbe estuary, Germany. Silicon. doi:10.1007/s12633-012-9131-1

9. Jacobs S, Müller F, Teuchies J, Oosterlee L, Struyf E, Meire P (2013) The vegetation silica pool in a developing tidal freshwater marsh. Silicon. doi:10.1007/s12633-012-9136-9

10. Struyf E, Conley DJ (2012) Emerging understanding of the ecosystem silica filter. Biogeochemistry 107:9-18

11. Viaroli P, Nizzoli D, Pinardi M, Rossetti G, Bartoli M (2013) Factors affecting dissolved silica concentrations, and nutrient stoichiometry in a human impacted watershed. Silicon. doi:10.1007/s12633-012-9137-8

12. Ronchi B, Vandevenne F, Pena Barão AL, Clymans W, Struyf E, Batelaan O, Dassargues A, Govers G (2013) Transport of dissolved Si from soil to river: a conceptual mechanistic model. Silicon. doi:10.1007/s12633-012-9138-7 